\title{
Dredge Volume Calculation Using Grid Volume Model at Sharm Obhur, Red Sea-A Case Study
}

\author{
V. R. Shamji \\ Faculty of Maritime Studies, King Abdulaziz University, Jeddah, Kingdom of Saudi Arabia \\ Email:vrshamji@gmail.com
}

How to cite this paper: Shamji, V.R. (2019) Dredge Volume Calculation Using Grid Volume Model at Sharm Obhur, Red Sea-A Case Study. Open Access Library Journal, 6: e5299.

https://doi.org/10.4236/oalib.1105299

Received: February 26, 2019

Accepted: March 11, 2019

Published: March 14, 2019

Copyright $\odot 2019$ by author(s) and Open Access Library Inc.

This work is licensed under the Creative Commons Attribution International License (CC BY 4.0).

http://creativecommons.org/licenses/by/4.0/

\section{Open Access}

\begin{abstract}
Calculation of dredging volume is very critical for project estimation and implementation. Many methods are available to compute the dredging volume and most of them are complex and expensive too. This paper proposes a simple grid volume numerical model to calculate the dredging volume. A case study conducted at Sharm Obhur, the Red Sea, using the grid volume model and quantitative analysis, was carried out. The study pointed out that the grid volume model is more precise and faster compared to other commercially available methods. The study has great practical potential for project plans, estimations and developments in the maritime sector.
\end{abstract}

\section{Subject Areas}

Environmental Sciences

\section{Keywords}

Dredging Volume, Numerical Calculation, Grid Volume Model

\section{Introduction}

Safety and cost effectiveness are the important factors in navigations and for better navigation, there needs to deepen the near-shore area, harbor, river, inlets, etc. In the dredging industry, quantifying the sediment is an important factor to estimate the cost of the project. The pre and post hydrographic survey is required for quantifying the amount of material to be dredged. Many methods are available for computing volume dredging to find the cost of the project [1]. Most of the available methods are commercial and are expensive. The available methods have their individual features and vary with accuracy in predictions [2]. Among the available methods, section method is a $2 \mathrm{D}$ model, while contour methods quantify sediments between two adjacent contour lines. However, these 
models are having large number of approximation to calculate the dredge volume. The widely use techniques are Grid model and Triangulated Irregular Network (TIN) models [3]. The TIN model can be effectively used with high-density data set (multi-beam and single beam) with the help of geographic information system (GIS) [4], but requires large number of environmental data, more computer memory and computation time which causes the project more expensive. Based on these constraints, the present investigations were carried out using Grid model volume calculation, which can be easily used to compute dredge volume with bathymetry data. The grid volume model requires less storage space and computation time and is cost-effective.

The present investigation carried out berthing area near the faculty of maritime studies in the Sharm Obhur, the Red Sea. The Sharm Obhur has an average maximum depth of $30 \mathrm{~m}$ at the center of the channel [5]. If any large survey vessel having more than $4 \mathrm{~m}$ draft cannot berth in the faculty berthing area. The bottom topography near to the berthing area is too shallow and has an average depth of $3 \mathrm{~m}$. In future, deepening of the berthing area will facilitate large survey vessel to berth near the faculty and it will worth for future facility. Hence, the present investigation was carried out for the quantitative assessment of dredging volume to deepen the berthing area for safe berthing of survey vessels having draft more than $4 \mathrm{~m}$.

\section{Methodology}

The primary and secondary data collated from the hydrographic department as part of the study and data were processed using different software accordingly. Dredged volume calculations need pre-dredge survey and other related surveys for better results. The hydrographic survey is a vital tool for planning and implementations of different stages of dredging projects, especially for ports and harbor [6]. The hydrographic data include multibeam data, sound velocity profile data, side scan sonar data, etc. The data processed using Caris Hips \& Sips v7.1 is and details were discussed in the following sections.

The proposed dredging area is in the Sharm Obhur channel, Red Sea (Figure 1). The said area is near to the navigation channel (Figure 2). The total area of dredging divided into two for computation and volume calculations.

Since the study area is not having a more complex topography and slope features, the grid volume method used for dredge volume computations. The grid model volume calculation is one of the most complete volume calculations methods in the dredging projects [7]. It facilitates the volume calculations for dredged channels, land surfaces etc. defined by the grid model. The volumes are calculated by creating two gridded surface of existing and design surface. The two surfaces have same the same number of rows and columns and the same $\mathrm{X}$ and Y limits. In the grid model, different mathematical techniques like Simpson's rule [8] and Trapezoidal rule [9] used for volume computation. The collected multibeam data made to equidistant grid data and the same is given as input in the grid model. The square grid coordinate system with easting and 


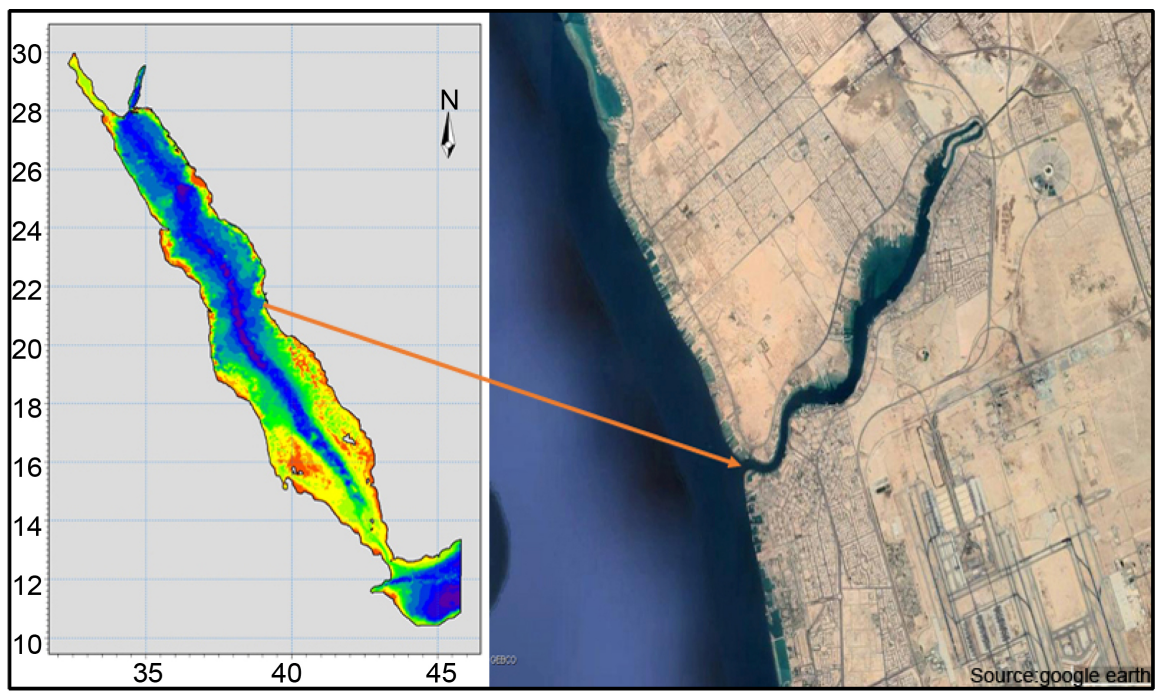

Figure 1. Study area.

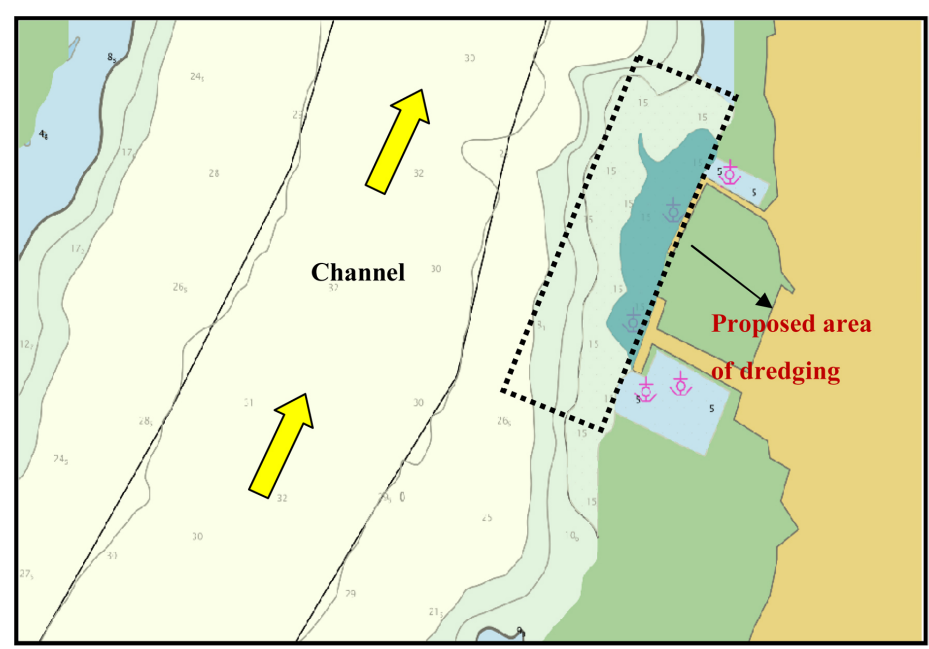

Figure 2. Proposed dredged area.

northing axis used in this system. The UTM (Universal Transverse Mercator System) is used as projection system.

\section{Result and Discussion}

The dredge volume calculated by selecting the proposed area into two separate sections (area 1 and area 2, Figure 3). Since dredging processes altering the natural conditions, dredging processes will have impacts on the environmental conditions [10]. The dredge volume calculations were performed by defining two surfaces, upper and lower surface. The present investigation was carried out by defining present topography of the proposed area as upper grid and lower surfaces (to be dredged) are defined by plane of constant level. The volume calculations become more accurate as the density of the grid is increased. The grids with significant "noise" or with highly irregular surfaces are not good for volume calculations. The volume was calculated using different mathematical in the grid 


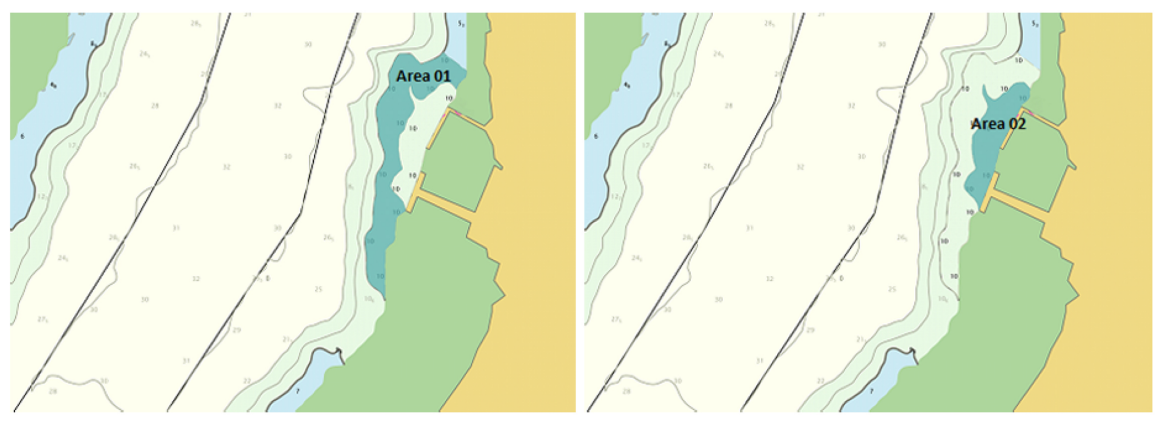

Figure 3. Proposed dredged area 1 and area 2.

volume model.

\subsection{Dredge Volume Calculations}

As discussed in the previous sections different mathematical techniques were used for volume computations. The volume computed at two areas separately and net volume computed using these calculations.

\subsubsection{Volume Calculation Area 1 and Area 2}

The computation was carried out by defining present topography of the proposed area as upper grid and lower surfaces (to be dredged) are defined by plane of constant level. The collected bathymetry data used to create an upper surface with fine grid spacing $1 \mathrm{~m}$ and the details are given in Table 1 . The lower surface is given by a constant value to specify the level of the planar surface to calculate the volume. In this present investigation the lower surface value is given is specified by $-10 \mathrm{~m}$ and volume calculated. The volume is calculated by creating grids of upper and lower surfaces. Since the lower surface is specified with constant value lower surface grid is not generated. The planar area and volumes of proposed area were calculated and details were given in the following Table 2. The same procedures were carried out for the computations of dredge volume for the area 2 and the details of volume computation are given in Table 2.

\subsubsection{Net Volume Calculations in Proposed Area}

The total dredge volume was calculated at proposed area by taking the algebraic sum of the volume calculated at area 1 and area 2 . The computed total volume at proposed area is $22,774.15 \mathrm{~m}^{3}$. Since the proposed lower surface having depth more than the upper surface in both the areas the negative volume is nil.

\section{Conclusion}

The present investigation is carried out in a small area, as a case study and hence the scope of further study needs more. The grid model volume calculation can be easily used to compute the dredge volume with topographical data. The present investigation is conducted as a primary study and can used for related studies having identical objectives. Since the proposed method has high precision, calculation efficiency, it can meet the requirements of many dredging projects 
Table 1. Details of upper surface grid surface of Area 1 and Area 2.

\begin{tabular}{cccc}
\hline Sl. No. & Details & Area 1 & Area 2 \\
\hline 1 & X Minimum (Easting) & $509,912.0$ & $509,929.2$ \\
2 & X Maximum (Easting) & $509,963.7$ & $509,963.7$ \\
3 & X Spacing (Easting) & $1 \mathrm{~m}$ & $1 \mathrm{~m}$ \\
4 & Y Minimum (Northing) & $2,400,621.0$ & $2,400,639.4$ \\
5 & Y Maximum (Northing) & $2,400,713.3$ & $2,400,713.2$ \\
6 & Y Spacing (Northing) & $1 \mathrm{~m}$ & $1 \mathrm{~m}$ \\
7 & Z Minimum (depth, m) & -8.23 & -4 \\
8 & Z Maximum (depth, m) & -5.3 & -3.2 \\
\hline
\end{tabular}

Table 2. Volume calculations of Area 1 and 2.

\begin{tabular}{cccc}
\hline Sl. No. & Calculation method & $\begin{array}{c}\text { Volume } \\
\text { (Area 01) }\end{array}$ & $\begin{array}{c}\text { Volume } \\
\text { (Area 02) }\end{array}$ \\
\hline 1 & Trapezoidal Rule: & $12,280.13 \mathrm{~m}^{3}$ & $10,494.02 \mathrm{~m}^{3}$ \\
2 & Simpson's Rule: & $12,350.96 \mathrm{~m}^{3}$ & $10,586.36 \mathrm{~m}^{3}$ \\
3 & Simpson's 3/8 Rule: & $12,349.43 \mathrm{~m}^{3}$ & $10,549.52 \mathrm{~m}^{3}$ \\
\hline
\end{tabular}

and can be applied to the areas not having a more complex topography and slope features. The present investigations have more importance in the field of academic research and developments.

\section{Acknowledgements}

The author thanks Dean, Faculty of Maritime Studies, King Abdulaziz University for support. I also thank Mohammad Omar Tatwany for his help during the preparation of the manuscript.

\section{Conflicts of Interest}

The author declares no conflicts of interest regarding the publication of this paper.

\section{References}

[1] Qin, W.X., Xie, X.H. and Zang, D.Y. (2007) Discussion on Earthwork Calculation Method for Land Leveling up in Zixi Industrial Area. Surveying and Mapping of Geology and Mineral Resources, 23, 11-13. (In Chinese)

[2] Miao, Z.J., Li M.C. and Zhong, D.H. (2012) Numerical Calculation of Channel Dredging Volume Using 3D Digital Stratum Model. Transactions of Tianjin University, 18, 90-96. https://doi.org/10.1007/s12209-012-1714-9

[3] Brouns, G., De Wulf, A. and Constales, D. (2001) Multibeam Data Processing: Adding and Deleting Vertices in a Delaunay Triangulation. Hydrographical Journal, No. 101, 3-9.

[4] Kalmár, J., Papp, G. and Szabó, T. (1995) DTM-Based Surface and Volume Approximation: Geophysical Applications. Computers and Geosciences, 21, 245-257. https://doi.org/10.1016/0098-3004(94)00069-7 
[5] Alaa, M.A. (2009) Water Exchange of Sharm Obhur, Jeddah, Red Sea. Journal of

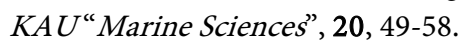

[6] Wack, R. and Wimmer, A. (2002) Digital Terrain Models from Airborne Laser scanner Data-A Grid Based Approach. International Archives of Photogrammetry Remote Sensing and Spatial Information Sciences, 34, 293-296.

[7] International Federation of Surveyors (FIG) (2010) Guidelines for the Planning, Execution and Management of Hydrographic Surveys in Ports and Harbours (Publication No. 56). Oriveden Kirjapaino, Finland.

[8] Simpson Rule, Back Ground, The Royal Academy of Engineering. http://www.raeng.org.uk/publications/other/2-earthworks

[9] Trapezoidal Rule, Back Ground. http://www.intmath.com/

[10] Bokuniewicz, H., Gebert, J.A., Gordon, R.B., Kaminsky, P., Pilbeam, C.C. and Reed, M.W. (1974) The Environmental Consequences of Dredge Disposal in Long Island Sound-Phase II. Report to the US Army Corps of Engineers, SR-8, Yale University, New Haven, CT. 